\title{
Creation and Implementation of High Technologies in Lithuania under Conditions of Globalization
}

\author{
Audronè Kvedarienè ${ }^{1}$, Laima Švedienè ${ }^{2}$, Giedrè Švedaitẻ ${ }^{3}$ \\ Department of International Economics and Business Management, \\ Vilnius Gediminas Technical University, Vilnius, Lithuania \\ E-mails: 'audrone.kvedariene@vgtu.lt (corresponding author); \\ 2laima.svediene@vgtu.lt; ${ }^{3}$ giedre.svedaite@stud.vgtu.lt
}

Received 27 February 2017; accepted 11 April 2017

\begin{abstract}
The development, dissemination and implementation of high technologies in Lithuanian market is a complex process within national innovation system. The comprehension of trends in the global market requires investigation of implications of regionalization, globalization and internationalization phenomena. EU policies significantly support R\&D though the efficiency of innovation commercialization is not far reaching comparing with the leading countries in high technologies development, dissemination and implementation. To overcome this European paradox and social, environmental challenges, EU Commission ascertained Innovation Union 2020 Strategy. The objective of this article is to explore the EU regionalization impact on Lithuanian high technology development, dissemination and implementation performance, therefore the value chain theories relevant for the global markets aspect are reflected.
\end{abstract}

Keywords: global markets, regional markets, high technologies, innovation union, global value chain, national innovation systems.

JEL Classification: M11, M16, M31, M38, D53.

Conference topic: Internationalization Processes: Contemporary Challenges.

\section{Introduction}

The aim of this article is to explore the processes in the international business environment and the historical context of high technologies significance in the development of multinational and global or regional approach to worldwide market. The latest theories are summarised evaluating the modern trends in global markets empowered by Fourth Industrial Revolution: the market segmentation shift from mass customisation to individual customised solutions. The considerable insights dedicated to comparatively new phenomenon - regionalization processes, highlighting in Europe Union integration course. The comparative analysis of EU high technologies industries demonstrate the evidence of European paradox. The scientific performance of EU comparing with the main partners is excellent, but over the last decades, the performance of high-technology sectors, particulary commercialization of electronics and information technologies is declining. It is a concern of strategic importance for the EU to propose an action plan empowering transformation of the scientific and technological research results and skills into the potential and viable innovations (EC 1995, Green Paper on Innovation). To overcome this deficiency and other challenges our society is facing EC in EU 2020 Strategy launched new initiative - Innovation Union to enable European governments and busineses to redeploy priorites for ensuring the competitiveness in high technologies industries.

The introduced Lithuanian case revealed that, European paradox is particularly relevant, though further research is required for establishment of required transformations in Lithuanian National Innovation System. The methods for value chain establishment are still extensively explored, while the complexity of innovation value chain is increasing, particularly regarding the enlargement of value chain networks level and consideration of economic activity sustainability.

\section{Globalization, internationalization and regionalization of the markets}

The H. Marshall McLuhan is known for coining the term global village in 1960s and for predicting the World Wide Web almost thirty years before it was invented (Levison 1999). Thought, only from 1980s the term globalization become a ubiquitous symbol of the new epoch. However, the unambiguous definition and significance of scale of

(C) 2017 A. Kvedarienè, L. Švedienè, G. Švedaitè. Published by VGTU Press. This is an open-access article distributed under the terms of the Creative Commons Attribution (CC BY 4.0) License, which permits unrestricted use, distribution, and reproduction in any medium, provided the original author and source are credited. 
globalization till nowadays exploited as the subject of debate. The foundation of these differences is that globalization is explored by number of disciplines severally from distinct perspectives (Clark, Knowles 2003). Thus, the term globalization is encountered in many fields such as economics, policy, and culture. In this sense, the globalization process is not single but linked processes of globalization, each of which requires to encounter a question: "The globalization of what?" (Quelch, Deshpande 2004).

In the business management academic analysis Levitt (1983) pronounced new attitude and actions needed to propel business management due to the globalization of markets. It was argued that the consumer similarities across national boundaries outweigh the differences and highlighted that "the one great thing all markets have in common an overwhelming desire for dependable world standard modernity in all things at aggressively low prices". The innovations in manufacturing processes and production technology, resulted high quality products that exploited the scale of economy due to "the simplicity and standardization" causing the convergence of tastes among consumers, therefore T. Levitt predicated that decentralized multinational corporations becoming obsolete and proposed to treat the entire world market as one global market with "homogenized demand" with the strategy to "sell the same things in the same way everywhere". T. Levitt correctly observed the technological change as a force for globalization, though for that time focusing not so much on information technology, but on the new technologies, that enabled the production at lower cost (Quelch, Deshpande 2004). Moreover, the radical technological innovations "proletarized communication, transport and travel" enabled "new commercial reality - the emergence of global markets for standardized consumer products on previously unimagined scale of magnitude" (Levitt 1983), due to the scale of economy not only in production, but also in distribution, marketing and management.

In 1983, when T. Levit proposed the global marketing concept, when only several prominent countries in Western Europe, North America and Japan the corporations had home divisions that export products and sold services outside the home country borders. The companies located in these nations generate the significant percentage of world trade, and approximately 32 percent of the world's population lived in communist countries conducting very little percentage of the trade (UN 1986). The barriers for trade actually encountered even capitalistic countries while tariffs, subsidies, technical standarts and other prohibitions were apparent for that time. When T. Levitt predicated about globalization, he excluded a large share of the globe (Quelch, Deshpande 2004).

The historical concern, comprehending globalization, particularly controversial analysing the past and shaping the future, therefore the attitude in different time epochs requires new answers to the question, "Is globalization today really different than globalization a hundred years ago?" (Bordo et al. 1999). It is obvious, that even today the markets for products and capital in fact are far from "perfect integration" (Ghemawat 2000) and it's far from the reality the issue to perceive and assess the world's market as "borderless" (Ohmae 1989). It has to be considered, the "borders" and distances of national markets may originate from several sources: culture (concerning race, language, religion, etc), geography, administration (embraces political and economic relationships) and economic inequality in welfare (Ghemawat 2000). One of the new phenomena of the early part of the twenty first century, which creates a new distances for markets, is the growth of nationalism, national pride, claiming that global marketers are engaged in a commercial imperialism. For the sovereign nations the resistance to the forces of globalization is largely ineffective. This is partly because the nation-state is a relatively new and fragile institution. Only four of today's nations - China, France, India, and the United Kingdom - existed in their current configuration more than 250 years ago. Three-quarters of today's sovereign states did not exist about fifty years ago (Quelch, Deshpande 2004).

T. Levitt argues, that globalization indicates a qualitative change in the character of the world's markets, not a quantitative change. He described the markets as global not due to the quantitative increase of the of capital flows among national borders, or that many countries have enlarged amount of the exports and imports, or the price of an undifferentiated product uniformity in different nations. For T. Levitt all those measures indicates the internationalization of the world economy and the globalization is a different concept that describes a change, which transforms the societies engaged in the internationalization processes. T. Levitt highlight that "the multinational and global corporation are not the same thing" (Levitt 1983). Global corporations function in a globalized economy, while multinational corporations operate in an internationalized economy. Globalization indicates economic activities within board less nations, whereas internationalization represents a quantitative increase of transactions across the borders of nations, which are controlled by governments that regulate openness. The multinational corporation produces products adjusted for the national markets, whereas the global corporation produces standardized homogenous products for all markets (Quelch, Deshpande 2004). Thus, the globalization defines the qualitative change: a new approach to an economic interactions with a societies appreciating the convergence of the preference of consumers. This attitude on globalization dominate in the emerging paradigm in the science of sociologists and politics of the world economy.

Thought, actually there are other trends for interpreting and understanding markets: neither globalization nor internationalization. Regionalization elucidate another prominent attitude explaining the situation markets (Lawrence 1996). Regional integration describes direction of increased economic exchange among nations of a region, and inevitably discriminating those outside it. EU, NATO, NAFTA, MERCOSUR and other regional organizations transformed the constellation of world's markets and the analysts of globalization cannot describe this phenomena. Each regional organization has its own cause, aims and evolution, leading countries including formal and informal political and economic relations (Katzenstein 1997a, 1997b). Thus due to regionalisation, the prime concern about the globalization of 
the product market, is expanded, including new areas of interests like the labour market, the financial market or technology market. In response to these new domains of interests the companies prefer regional strategy, instead of the global or the local strategy.

\section{The fifth freedom of Innovation Union}

European Union demonstrate profound regional market development, with the explicit political declaration, that long term challenges may be overcome if European nations will act collectively (COM 2010). EU region covered main four freedoms: free movement of goods; free movement of capital; free movement for workers and freedom to establish and to provide services. The EU Council conclusions on the definition of a 2020 Vision for the European Research Area (ERA) provided that by 2020, all EU countries will get advantage from the 'fifth freedom' within the ERA: free movement of researchers, knowledge and technology. The EU policy provided in ERA vision targeted to create favourable governance, enabling pursue the research by fostering Europe-wide scientific competition and induce investments in innovative high added value sectors in Europe, providing the relevant administration for the coordination. This strategy supposed to response to the demands of EU citizens needs to develop sustainable and competitive European market (European Competitiveness Council 2009). It is foreseen to achieve strong mutual interactions between elements of the 'knowledge triangle': education, research and innovation. This 'knowledge triangle' would encouraged cooperation at all innovation stages, starting from the researchers by funding public organisations such as universities and private companies including as SMEs as well as multinational companies providing appropriate European administration mechanisms. The ERA asserted that European to approach superiority in research is a principal remedy for European competitiveness in the globalised world.

European research and innovation policy over the past decade focused considerably on increasing inputs to innovation. In 2002 the Barcelona goal was announced, aimed at bringing R\&D expenditure in the EU to 3 percent of GDP by 2010 . When this target was not reached, in the Europe Strategy 2020 was set as the new target. Eurostat statistics shows that in 2015 the average of R\&D expenditures of EU -28 is still about 2 percent of GDP while US invest more than 2.5 percent, South Korea 4 percent and Japan 3.5 percent (Fig. 1).

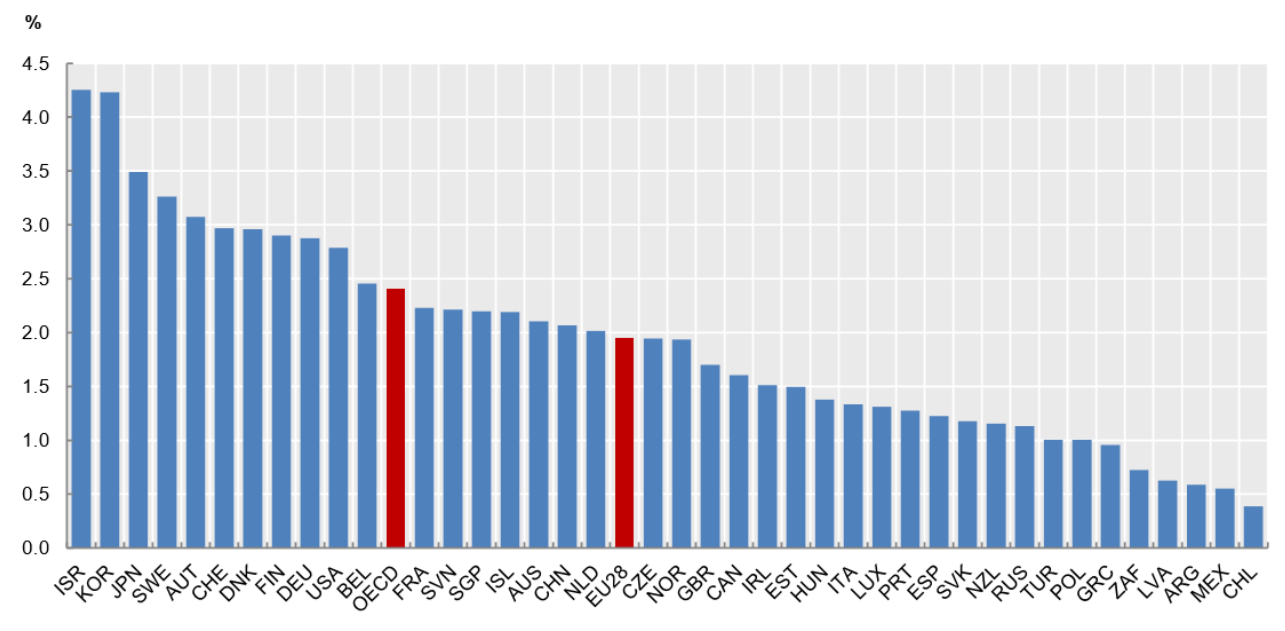

Note: Argentina, Canada, Ireland, Turkey, and Singapore figures refer to 2014. Australia, New Zealand, and South Africa figures refer to 2013. Switzerland figure refers to 2012.

Fig. 1. R\&D intensity in, 2015 (Source: OECD 2017, Main Science and Technology Indicators Database)

Evaluating the performance of The Commission services experimented with different approaches to develop and measure the innovation indicator and finally presented the Innovation Indicator, combining four individual indicators intended to measure innovation outputs and outcomes into a single composite indicator: (1) patent applications, (2) economic significance of knowledge-intensive sectors, (3) trade performance of knowledge-intensive goods and services and (4) significance of fast-growing firms in innovative sectors. Since tools such as Innovation Indicator are not only used as a purely informational basis but also feed into evidence based policy advice, e.g. country specific recommendations within the Europe 2020 strategy or smart specialisation initiatives, the adequacy of the information provided becomes crucial (Janger et al. 2017).

The most attempts to measure innovation are focused on innovation inputs, in particular R\&D based on Frascati Manual (OECD 2015) and human resources for innovation based on Canberra Manual (OECD, Eurostat 1995). Despite these approaches have been successful in terms of delivering comparable international data on the input side, comparable and reliable indicators on innovation outputs and outcomes at the country-level are still largely missing in spite of the efforts of the Oslo Manual (OECD 2005) to harmonise measurement of innovation output and outcomes (Godin 
2003, 2007; Freeman, Soete 2009). The literature on the innovation production function (e.g. Roper et al. 2008) is a starting position to derive country level indicators of innovation outputs and outcomes.

The EU countries leading in global performance providing scientist output when measured in terms of academic importance, the results of university research are excellent, but the ability to convert this strength into goods and services for the economic welfare, these results becomes marginal. This phenomenon, coined in a European Commission Green Paper as 'European paradox', triggered implementation of Innovation Union (IU) initiative. Implementing IU targets at regional EU level will be focused: to complete European Research Area; to cope with challenges such as energy security and resource efficiency, environmentally-friendly production methods, ageing of European population; to refine the business environment framework securing innovations (like single EU Patent and Patent Court organizations in order more efficiently to protect Intellectual Property); to promote 'European Innovation Partnerships' between the EU and national levels forcing the development and deployment of technological innovations in regarding the defined challenges; to elaborate other EU instruments to stimulate innovation; to encourage relations between education and business also through the European Institute of Innovation and Technology; to support Young Innovative Companies. EU Member States fulfilling IU policies at national level have: to improve national innovation systems performance to expand smart specialisations, strengthen partnership between education, research and business, particularly inducing cross-border liaison; to promote engineering graduates and education curricula on creativity, innovation; to provide instruments to prompt the private investments to the R\&D.

The concept of a national innovation system is developed to ascertain how different institutions intertwine at the national level through the generation and the diffusion of innovations. The expenditures on research is the driving force for innovation thought the development the territorial concentration, economic dimension, numbers of researchers, scale and variety of laboratories, previous researches on whose bases new researches are developed, introduction of researchers and laboratories into the international scientific community and trans-national research network have to be considered. Therefore the approach to 'national innovation systems' has to be applied in the R\&D intensive sectors (Lundvall 1992; Nelson 1993) in order to redefine performance at a local level, it is required to set up activities in a regional level that enables activation of new local industries (Cooke, Morgan 1998). Successful development of high technologies is primarily inseparable from the 'triple helix' model: the academic public - industry - government integration. This model describes the nature of processes, while the public sector promotes the national high technologies industry in some extent to lower the risk for the private sector, thus encourages the academic public to generate innovative ideas of technologies and enforces the private sector implement these ideas (Chlivickas et al. 2010). It is required to elaborate appropriate public administration of academic scientific and industry performance to ensure efficient national innovation systems which enables national high technology industries to operate in the global markets.

Europe 2020 Strategy puts forward three mutually reinforced priorities: smart growth (the knowledge and innovations appointed as the fundamentals for economic development); sustainable growth (environmental issues considered as vital); inclusive growth (social and territorial cohesion) (COM 2010). These strategic priorities obviously provides the vision of Europe's social market economy for the 21st century. Measuring the national and European innovations performance becoming significantly complex whereas these priorities are mutually interrelated.

\section{Global Value Chain Management}

The trends of globalisation and latter regionalisation induces the expansion of organisations' international partnership. The changing perception to organization strategy, structure and location, approaching to organisations as partners within networks, operating as product-services providers within specialist markets is significant (Walters 2011). In a dynamic business environment, caused by deregulation, technological innovation, industry consolidation and shifted consumer demands, the new methods have to be introduced create value and diffuse value (Martin 2011). The aim of value chain management theory is to describe, to define and to conduct the entire network of appropriate business partners in order to provide superior value to consumer and to ensure sustainable economic development including partners as well as other interest parties. Since the early 1980s European capitalism follows Anglo-American business model, based on a shareholder value philosophy (Fligstein 2005). Other possible stakeholders' value objectives of welfare of consumer, employment stability, or other broader social or environmental goals, are not considered (Barker 2010).

Since the late 1980s, the necessity to create economies of scale encouraged the tendency to centralize outsourcing of multinational and global corporations and to globalize suppliers in order to refine their competence and expanded their productive capacity over time, strengthening the demand to create stronger global value chains, exploiting location advantages across nations and regions, adding value by connecting globally dispersed inputs so as to better serve their clients.

In modern economy many industrial markets oriented not to the product, but to solution markets: the customers are acquainted with available product application but are also significantly influenced by service-maintenance possibilities instead of preferring lower prices, hence this approach used by many manufacturers. Therefor to become effective nowadays it is substantial the mutual understanding of suppliers and customers expectations (value driver) and costs (value driver response costs) (Walters 2011). The network approach encourage the complexities of markets in 
which solutions to customers' will cross a number of international borders and various of intra and inter organisational boundaries during the value transformation process (Walters 2011). In addition technology related trends enables cocreativity - the implication of consumers in the creation of product value that meet particular needs of customers; co-productivity is operational participation by suppliers, distributors and customers.

The Fourth Industrial Revolution offer stunning prospect of higher economic growth and societal progress. Developed on the digital platforms, the Fourth Industrial Revolution is described as a convergence of technologies that embraces the physical, digital, and biological fields. The Global Competitiveness Report (2016-2017), highlight technologies such as robotics, artificial intelligence, biotechnology, 3D printing and the Internet of Things will provide new inspiration for economic development and growth in the near future but also imply significant social challenges. It is anticipated that factories tend to be expanded production facilities in a global network though could be managed as single virtual factory. This model of manufacturing network would consolidate multiple resources and capabilities to form an end-to-end fulfilment network that could be coined as fulfilment execution system. This implication of 'emerging business explicitly commented by Iansiti, and Levien (2004) as "the art of managing assets that one does not own". The business models as networks apparent in modern economy, thus the presumption that pervasive networked format of the business environment will induce evolution of business networked performance and new severities for managers (Walters 2011).

In the 1990s mass-customisation was prevalent competitive advantage and individual offers perceived as exclusiveness; next generation intelligent manufacturing systems identifies potential of customised solutions introducing supply of uniqueness rather exclusiveness. It is asserted that offering customised solutions the lowest market price strategy won't be a sufficient competitive advantage, the foremost market demand for the most effective and efficient solution provider (Walters 2011). "The industrial revolution of the eighteenth century made possible the mass production of goods, thereby creating economies of scale which changed the economy - and - society - in ways that nobody could have imagined at the time. Now a new manufacturing technology has emerged which does the opposite" (The Economist 2011).

The network value chain framework has changed the nature of economics based on limited perception of scale economics, to a collective concept referred as dispersed value chain when operations: development, production, delivery and service provision accomplished by range of participants founded on various relations statuses and locations.

Multinational enterprises nowadays can be considered the as key actors in the globalization process, as a relatively small number of them comprise the significant share of the world's trade and direct investment. Contemporary these diversified multinational conglomerates transforming to global specialists and narrowing product diversification by globalfocusing to niche markets and competing with a limited number of participants operating worldwide (Meyer et al. 2006). The mass-customisation, globalfocusing and dispersed solutions, enabled by technological innovation, obviously contribute to global hypercompetition. Under conditions of hypercompetition, assumptions of market stability are replaced by notions of inherent instability and change, when competition based on: price-quality positioning, foundation of new know-how and first-mover advantage, invasion and protection of established product or geographic markets. To explain this competitive dynamics, the effects of varying rates of competitive speed in different markets has to be explored and identified as slow-cycle, fast-cycle, and standard-cycle markets and the behaviour of all competitors within a given market has to be evaluated.

Globalization processes and modern technologies causing dynamic environmental circumstances and leads the augmentation of complexity in economic value networks. Practitioners and scientists perceive this complexity development but sufficient means to successfully handle complexity in such networks are not available yet (Schuh et al. 2008). This negatively affects internal enterprise planning and steering as well as the coordination of the surrounding network, thus current theories trend based on deduction of complexity-related parameters for determination of 'critical' locations in a value network under given business conditions (Engelhardt-Nowitzki et al. 2011; Manson 2001).

\section{The performance of Lithuanian high technologies industries}

Investigating the Lithuanian innovation indicators scoreboard provided by Eurostat, it can be referred that comparing with the EU member states the main strengths of Lithuania's research and innovation system are the size of its public research sector and it's not far from EU average and the supply of new graduates. The weaknesses reveal the scarce of private and public R\&D investments and investments remain below EU 2020 Strategy intensity target of $1.9 \%$ of GDP, also these investments are undertaken in a dispersed way and currently not linked to a smart specialisation strategy (EC 2014). Smart specialisation of EU policy is focused to identify unique characteristics and assets of each country and region, highlighting each region's competitive advantages, and rallying regional stakeholders and resources around an excellence-driven vision of their future. It is sated that these means of smart specialization strategy enables the strengthening of regional innovation systems by ensuring knowledge flows and spreading the benefits of innovation throughout the entire regional economy.

In Lithuania there is a low share of medium-tech and high-tech industries, low numbers of knowledge-intensive start-ups and the low rate of entrepreneurship, thus for Lithuanian private sector it is difficult to reach the national commitment to the R\&D target and it remains one of the lowest in the EU (EC 2014). The Figure 2 illustrates the 
upgrading of knowledge in different manufacturing industries for the period of 2008-2011 in Lithuania. The position on the horizontal axis shows the changing weight of each industry sector in value added over the period. The general trend to the vertical axis side reflects the decline of manufacturing in the overall economy. The sectors above the $\mathrm{x}$-axis are those where research intensity has increased over the period. The size of the bubble represents the sector share (in value added) in manufacturing (for all sectors presented on the graph) (EC 2014).

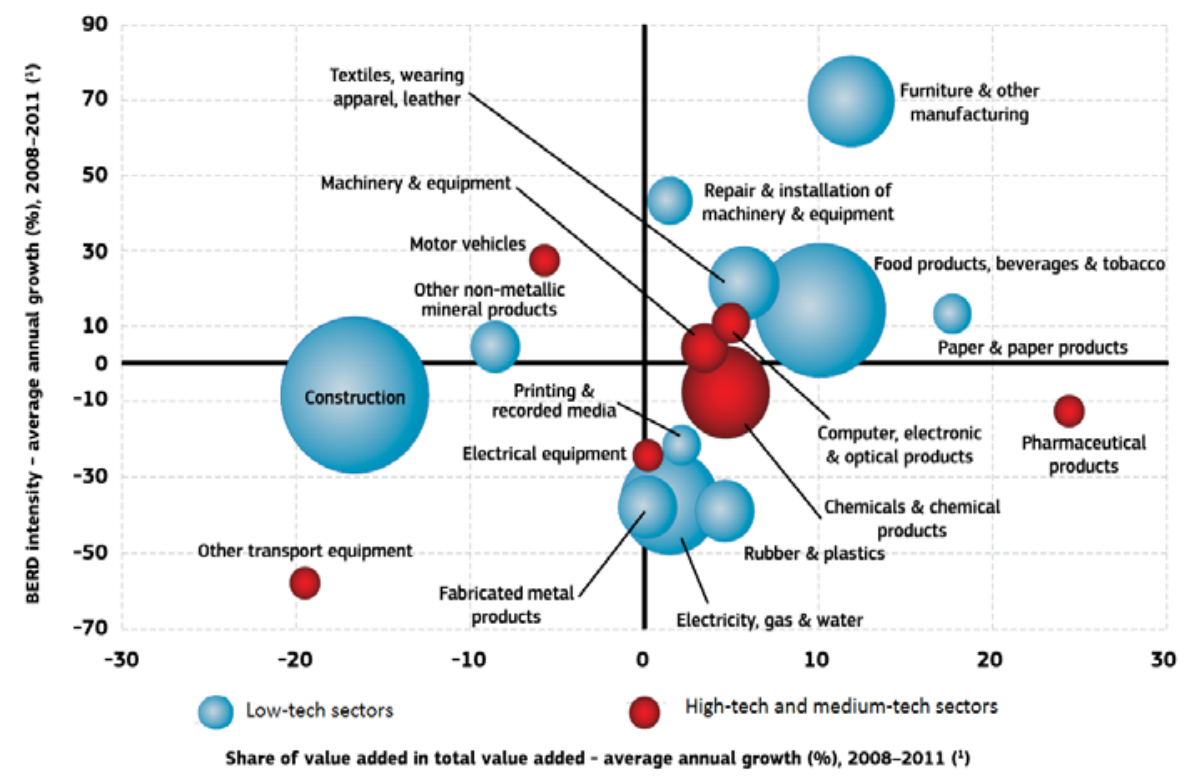

Fig. 2. Lithuania - share of value added versus business enterprices R\&D expenditures (BERD) intensity: average annual growth, 2008-2011 (Source: EC 2014)

Note (1) Furniture and other manufacturing: 2009-2011.

The Figure 2 indicates that in Lithuania's manufacturing industry dominates the low-tech and medium-low-tech sectors, which are intrinsically less research intensive than high-tech and medium-high-tech sectors. The only sizeable medium-high-tech sector is chemicals although in recent years it has received fewer business R\&D investments and currently accounts for less weight in the economy. The other high-tech and medium-high-tech sectors in Lithuania are small and import and re-export comprises a large part of the activity for some of them. As a result, the structure of this sector limits the overall level of business R\&D intensity in the country. The Figure 2 includes data on the crisis in 2009-2010 which affected some sectors - notably, the construction sector has declined significantly since that period. Two sizeable sectors possessed positive growth trends during 2008-2011: food products, beverages and tobacco, furniture and other manufacturing (EC 2014). The total effect of the evolution of the high-tech and medium-high-tech manufacturing sectors on overall business R\&D intensity in Lithuania has been limited. The chemical sector is clearly the most important medium-high-tech/high-tech sector in Lithuania in terms of size, although in terms of evolution its importance has decreased (EC 2014).

Research and Innovation performance report (EC 2014) highlights Lithuanian market limitations: insufficient science base competitiveness; lack of science connections to European networks; laggard of knowledge transfer and commercialisation; obvious low investments of private sector to R\&D. Therefore, Lithuania still performs at a low level sectors regarding the innovativeness of fast-growing firms. This is the result of a high share of employment in low-tech manufacturing, transportation, and construction companies among fast-growing enterprises (EC 2014).

To overcome this obstacle and to get competitive advantage in high technology markets, EU 2020 strategy foreseen the diversification of countries by focusing on several smart specialization sectors. This strategy in $2015 \mathrm{~s}$ adopted by Lithuanian Programme for the Development Priority Areas of Research and Experimental Development and Innovation and Implementation of Priorities. However, it has to be considered that diversification provokes the potential risk of generating a dual economy (between protected hi-technology areas and a traditional non-competitive economy). The many experiences of protected areas for high technology development, including 'maquiladoras' and the rest of export processing zones in developing economies, show the strong risk of merging two economies that do not interact with one another; the first being directly oriented to the international market, whereas the second remains totally focused on local markets (Parrilli et al. 2008). This dual economy phenomenon may be reinforced by foreign direct investments (FDI) when "attractive" economic activities will lead high FDI intensity rations and "unattractive" economic activities with low FDI intensity ratios (Tvaronavičiene, Grybaite 2007). Therefore, developing national innovation systems, promoting high technology industries, the dimensions of sustainable and inclusive competitiveness rather global, regional or national competitive advantages has to be considered (Balkyte, Tvaronavičiene 2010). 
Further investigations of national innovation systems' value chain performance has to be performed in order to identify limitations and strengthen every link, starting from the 'blue sky' research to commercialisation also evaluating the impact to the society and environment while oversimplified input and output innovation indicators may lead to failure in global competition as well to the outstanding social and environmental challenges.

\section{Conclusions}

The predominance peculiarity of high technology industries is a high risk activity, which requires long term investments to $R \& D$, therefore nations and regions attempt to promote development of high-technology industries. The firms in high-technology industries tend to be small and medium-sized, suggesting that industry policy toward this sector might optimally be different from policies that would be direct toward firms in other industries and sectors. In Europe 2020 Strategy Commission represents targeted EU key parameter for the investments in: research and development, education and resource efficient technologies. It is stated the aim of the policy is to benefit traditional sectors, rural areas as well as high skill, service economies and to reinforce economic, social and territorial cohesion. Mentioned priorities contradict with Commission recommendation to diverse economy and invest in selected smart specializations, obviously for ability to compete in high technology industries in a global market. The Commission pursue subsidiary principle that each Member State is different and diverse, but EU key targets have to be translated into national targets and trajectories considering the current situation of each Member.

One of the main EU 2020 strategy targets is to reach 3\% of the EU's GDP investment in R\&D, to improve the country's capacity to exploit research and innovation results commercially, will not just require develop a business environment prone to innovation but will also need a better skills base in higher education and incentives to engage the researchers in the public sector participate in knowledge transfer and commercialisation activities. Following EU social and cohesion political track, the effect of disruptive technologies, that create new markets but may destroy current value chains, has to be considered although in Europe 2020 strategy this challenge is not explicitly depicted.

The current market trends like customised solutions and globally networked value chains require the future production environment to be highly adaptable and reconfigurable to respond to rapid changes in market demand, technology innovation and changing regulations. Future enterprises will continuously reconfigure their operations with business units, thus the context of virtual value chain networks on a project basis trend will become significant, delivering customized solutions. The virtual chain models based on value creation for shareholders enables the exploration of the global links, thus regional EU sustainability policies are uncertain.

Further evolution of complexity of value chains will originate from the: globalization, internationalization and regionalization processes; convergence of high technologies- manufacturing, information technologies and biotechnologies; the share of corporation proliferation, merges and acquisitions, alliances, offshoring and outsourcing activates; enabled cocreativity and coproductivity of consumers; public demand for sustainable attitude to business models. Thus the methods for value chain evaluation in a global markets should be investigated contributing for businesses as well as for the public sector performance evaluation.

\section{References}

Balkyte, A.; Tvaronavičiene, M. 2010. Perception of competitiveness in the context of sustainable development: facets of "sustainable competitiveness", Journal of Business Economics and Management 11(2): 341-365. https://doi.org/10.3846/jbem.2010.17

Barker, R. M. 2010. Corporate governance, competition, and political parties. Explaining corporate governance change in Europe.

Bordo, M. D.; B. Eichengreen, B.; Irwin, D. A. 1999. Is globalization today really different than globalization a hundred years ago? S. Collins, L. R. Brookings (Eds.). Trade Policy Forum.

Chlivickas, E.; Petrauskaite, N.; Ambrusevič, N. 2010. Leading priorities for development of the high technologies market, Journal of Business Economics and Management 10(4): 321-328. https://doi.org/10.3846/1611-1699.2009.10.321-328

Clark, T.; Knowles, L. L. 2003. Global myopia: globalization theory in International Business, Journal of International Management 9(4): 361-372. https://doi.org/10.1016/j.intman.2003.08.007

COM. 2010. Europe 2020. A European strategy for smart, sustainable and inclusive growth.

Cooke, P.; Morgan, K. 1998. The associational economy: firms, regions and innovation. Oxford University Press. 247 p. https://doi.org/10.1093/acprof:oso/9780198290186.001.0001

EC. 2014. Research and innovation performance in the EU. Innovation Union progress at country level.

Engelhardt-Nowitzki, C.; Gerschberger, M.; Staberhofer, F. 2011. Complexity in global value networks: facilitation of value network boundary spanning decisions from a complexity perspective, in $1^{\text {st }}$ International Conference on Value Chain Management.

European Competitiveness Council. 2009. Conclusions of the Council on the definition of a '2020' vision for the European research area, Official Journal of the European Union C 25/01, 1-4 p.

Fligstein, N. 2005. The end of (Shareholder Value) ideology? Political Power and Social Theory 17: 223-38. https://doi.org/10.1016/S0198-8719(04)17010-5 
Freeman, C.; Soete, L. 2009. Developing science, technology and innovation indicators: what we can learn from the past, Research Policy 38(4): 583-589. https://doi.org/10.1016/j.respol.2009.01.018

Ghemawat, P. 2000. Economic evidence on the globalization of markets. Harvard Business School, 701-715.

Godin, B. 2003. The emergence of S\&T indicators: why did governments supplement statistics with indicators? Research Policy 32: 679-691. https://doi.org/10.1016/S0048-7333(02)00032-X

Godin, B. 2007. Science, accounting and statistics: the input-output framework, Research Policy 36: $1388-1403$. https://doi.org/10.1016/j.respol.2007.06.002

Iansiti, M.; Levien, R. 2004. Strategy as ecology, Harvard business review (March): 68-78.

Janger, J.; Schubert, T.; Andries, P.; Rammer, C.; Hoskens, M. 2017. The EU 2020 innovation indicator: a step forward in measuring innovations outputs and outcomes? Research Policy 46: 30-42. https://doi.org/10.1016/j.respol.2016.10.001

Katzenstein, P. J. 1997a. Asian regionalism in comparative perspective. Ithaca, N.Y.: Cornell University Press.

Katzenstein, P. J. 1997 b. United Germany in an Integrating Europe. Ithaca, N.Y.: Cornell University Press.

Lawrence, R. Z. 1996. Regionalism, multilateralism, and deeper integration. Washington, D.C.: Brookings.

Levison, P. 1999. Digital McLuhan: a guide to the information millenium. London: Routledge.

Levitt, T. 1983. The globalization of markets. Harvard Business Review, 92-103.

Lundvall, B. A. 1992. National innovation systems: towards a theory of innovation and interactive learning. London: Pinter Publishers.

Manson, S. M. 2001. Simplifying complexity: a review of complexity theory, Geoforum 32(3): 405-414. https://doi.org/10.1016/S0016-7185(00)00035-X

Martin, G. 2011. Evaluating the effectiveness of experiential learning for motivating value chain stakeholders to adopt new ways of capturing value, in $1^{\text {st }}$ International Conference on Value Chain Management.

Meyer, K. E.; Tran; Y. T. T. 2006. Market penetration and acquisition strategies for emerging economies, Long Range Planning 39(2): 177-197. https://doi.org/10.1016/j.lrp.2006.04.004

Nelson, R. R. 1993. National innovation systems: a comparative analysis. Oxford: Oxford University Press.

OECD. Eurostat. 1995. Measurement of scientific and technological activities: manual on the measurement of human resources. Devoted to S\&T - Canberra Manual. OECD Publishing.

OECD. Eurostat. 2005. Oslo manual: guidelines for collecting and interpreting innovation data. $3^{\text {rd }}$ ed. OECD Publishing.

OECD. 2015. Frascati Manual 2015: Guidelines for collecting and reporting data on research and experimental development, the measurement of scientific, technological and innovation activities. OECD Publishing.

Ohmae, K. 1989. Managing in a borderless world. Harvard Business Review.

Parrilli, M. D.; Bianchi, P.; Sugden, R. 2008. High technology, productivity and networks. A systemic approach to SME development. Palgarve Macmillan. https://doi.org/10.1057/9780230583726

Quelch, J.; Deshpande, R. 2004. The global market. Developing a strategy to manage across borders. Jossey-Bass.

Roper, S.; Du, J.; Love, J. H. 2008. Modelling the innovation value chain, Research Policy 37: 961-977. https://doi.org/10.1016/j.respol.2008.04.005

Schuh, G.; Sauer, A.; Doring, S. 2008. Managing complexity in industrial collaborations, International Journal of Production Research 46(9): 2485-2498. https://doi.org/10.1080/00207540701737781

The Economist. 2011. How a new manufacturing technology will change the world [online], [cited 15 February 2017]. Available from Internet: http://www.economist.com/node/18114327

Tvaronavičiene, M.; Grybaite, V. 2007. Impact of FDI on Lithuanian economy: insight into development of main economic activities, Journal of Business Economics and Management 8(4): 285-290. https://doi.org/10.1080/16111699.2007.9636181

United Nations. 1986. Department of international economic and social affairs. Statistical Office, 1983/84 Statistical Yearbook, $34^{\text {th }}$ ed. New York: United Nations, 6, 62-68.

Walters, D. 2011. Competition, collaboration, and creating value in the value chain, in Selected Papers of the $1^{\text {st }}$ International Conference on Value Chain Management, 4-5 May 2011, University of Applied Sciences in Upper Austria School of Management, Steyr/Austria, 3-36. 